\title{
11
}

\section{THE MEDIA ARCHAEOLOGY LAB AS PLATFORM FOR UNDOING AND REIMAGINING MEDIA HISTORY}

\author{
Lori Emerson
}

It is hard not to notice the rapid proliferation of labs in the arts and humanities over the last ten years or so - labs that now number in the thousands in North America alone and that are anything from physical spaces for hands on learning and research to nothing more than a name for an idea or a group of people with similar research interests, or perhaps a group of people who share only a reading list and have no need for physical space and no interest in taking on infrastructural thinking through shared physical space. Regardless of their administrative organization, focus, funding, equipment or outputs (or lack thereof), the proliferation of these labs reflects a sea-change in how the humanities are trying to move away from the nineteenth-century model of academic work typified by the single scholar who works in the boundaries of a self-contained office and within the confines of their discipline to produce a single-authored book that promotes a clearly defined set of ideas.

Instead, humanities scholars seem to be rallying around the term 'lab' (along with 'innovation' and 'interdisciplinary' and 'collaborative' - terms that are all invoked whenever the topic of labs come up), likely because this particular term and structure helps scholars put into better focus their desires for a mode of knowledge production appropriate to the twenty-first century - what one might call 'posthumanities' after Rosi Braidotti's articulation of it in The Posthuman as a humanities practice focused on human-non-human relationships, "heteronomy and multi-faceted relationality" and one that also openly admits, in Braidotti's words once more, that "things are never clear-cut when it comes to developing a consistent posthuman stance, and linear thinking may not be the best way to go about it". For me, in more concrete terms, this version of posthumanities work means pursuing modes of knowledge production that are quick on their feet, responsive, conversational or dialogical, emergent, collaborative, transparent, and self-conscious. They are interested in recording their knowledge production 
processes, and experimental about what constitutes a rigorous knowledge production and distribution process. These are perhaps by now tired clichés of the kind of work many would like to do, many believe they do, and that many administrators would like to see humanists do; but it is still worth noting that - more because of a longstanding lack of access to both material and immaterial resources than a lack of imagination - very few are actually able do this kind of work. This trend to create labs, even if only in name, is also a response to pressures humanists are feeling to both legitimize and even 'pre-legitimize' what they do as increasingly they are expected not just to 'perform' but, more importantly, to prove they're performing. The proof of performance is possibly now more important than the performance itself. And where else do we get our ideas about 'proof but from some notion of how the sciences are in the business of proving the rightness or wrongness of theories about reality by way of the 'discovery' of facts that takes place in a laboratory environment?

As popular figures in Science and Technology Studies such as Bruno Latour (particularly in his classic Laboratory Life from 1979, co-written with Steve Woolgar) and Donna Haraway (in her essay "Situated Knowledges: The Science Question in Feminism and the Privilege of Partial Perspective", 1988) have been teaching us for several decades: these notions about proof and the scientific method do not need to have any grounding in how scientific truth is actually produced or manufactured - it is more about trying to figure out why the continual circulation of a particular cultural belief is necessary. I have come to see that the staying power of this belief about the nature of proof and scientific practice is derived not so much from scholars' obliviousness or ignorance about these convention-bound processes of legitimation but instead from the importance of maintaining belief in humanism, even though it appears we are just talking about science. A belief about how scientists 'discover' truth depends on the related belief that scientists are not affected by the agency of their tools, machines, the outside world, other people (Latour and Woolgar 1986). This is a belief that is a cornerstone of humanism and thus it is just as much a part of the humanities as it is a part of the sciences, for the prevailing belief in the humanities seems to be that humanists are also not affected by their tools, machines, the outside world, other people. Microsoft Word is simply a tool I use to produce articles and books. Google is simply a search engine I use to discover relevant information. The Graphical User Interface just happens to be the easiest way for me to interact with my computer. Regardless of the constant admonition from administrators to innovate, collaborate, incubate and whatever other entrepreneurial terminology you can think of, at the end of the day our raises, appointments, ability to get jobs, and much else besides, depends on continually manufacturing the illusion of a clear separation between ourselves, others, and the rest of the material world.

It is true that some humanities labs appropriate a traditional notion of labs from the sciences as a way to continue humanism but they do so under the auspices of innovation - the Stanford Literary Lab, when it was under the directorship of Franco Moretti, is the most well-known example of this as Moretti described 
the lab's main project of 'distant reading' as one driven by the desire for "a more rational literary history" because "[q]uantitative research provides a type of data which is ideally independent of interpretations" (Moretti 2003, 72). But, these instances aside, what does a uniquely humanities lab look like - or what could such a lab look like if it did not feel compelled to respond to the aforementioned pressures to perform and 'objectively' measure such performance? How could such a lab even creatively make the most of its more limited access to the kinds of resources large science labs depend on and instead embrace what I called above the posthumanities?

The Lab Book: Situated Practices in Media Studies (forthcoming from the University of Minnesota Press and co-written by me along with Jussi Parikka and Darren Wershler) investigates the history as well as the contemporary landscape of humanities-based media labs - including, of course, labs that openly identify as being engaged - in terms of situated practices - with the digital humanities. Part of the book's documentation of the explosion of labs or lab-like entities around the world over the last decade or so includes a body of over 60 interviews with lab directors and denizens. The interviews not only reveal profound variability in terms of these labs' driving philosophy, funding structures, infrastructures, administration, and outputs. They also clearly demonstrate how many of these labs do not explicitly either embody or refute scientificity so much as they pursue twenty-first-century humanities objectives (which could include anything from research into processes of subjectivation, agency, and materiality in computational culture to the production of narratives, performances, games, and/or music) in a mode that openly both acknowledges and carefully situates research process as well as research products, the role of collaboration, and the influence of physical and virtual infrastructure. While, outside of higher education, 'lab' can now refer to anything from a line of men's grooming products to a department store display or even a company dedicated to psychometric tracking, across the arts and humanities 'lab' still has tremendous, untapped potential to capture a remarkable array of methodically delineated and self-consciously documented entities for experimentation and collaboration that may or may not include an attention to history - though they almost always include an emphasis on 'doing' or hands on work of some kind.

I also view The Lab Book as an opportunity to position the Media Archaeology Lab (MAL) in the contemporary landscape of these aforementioned humanities/ media labs. Since 2009, when I founded the MAL, the lab has become known as one that undoes many assumptions about what labs should be or do. Unlike labs that are structured hierarchically and driven by a single person with a single vision, the MAL takes many shapes: it is an archive for original works of early digital art/ literature along with their original platforms; it is an apparatus through which we come to understand a complex history of media and the consequences of that history; it is a site for artistic interventions, experiments, and projects; it is a flexible, fluid space for students and faculty from a range of disciplines to undertake practice-based research; it is a means by which graduate students come for hands on training in fields ranging from digital humanities, literary studies, media studies, 
and curatorial studies to community outreach and education. In other words, the MAL is an intervention in 'labness' insofar as it is a place where, depending on your approach, you will find opportunities for research and teaching in myriad configurations as well as a host of other, less clearly defined activities made possible by a collection that is both object and tool. My hope is that the MAL can stand as a unique humanities lab that is not interested in scientificity but that is instead interested in experiments with temporality, with a see-saw and even disruptive relationship between past, present, and future, and in experiments with lab infrastructure in general.

\section{From Archaeological Media Lab to Media Archaeology Lab}

The MAL is now a place for hands on, experimental teaching, research, artistic practice, and training using one of the largest collections in North America of still functioning media spanning roughly a 130 year period - from a camera from 1880 , a collection of early twentieth century magic lanterns and an Edison diamond disc phonograph player to hardware, software and game consoles from the mid-1970s through the early 2000s. However, the MAL initially came to life in 2008-2009 as the Archaeological Media Lab. At that time, the field of media archaeology had not yet become well known in North America and the lab was nothing more than a small room on the campus of the University of Colorado at Boulder containing 15 Apple IIe computers, floppy drives, and copies on 5.25" floppy disks of a work I had come to admire very much: First Screening, one of the first (if not the first) digital kinetic poems created by the Canadian experimental poet bpNichol.

I began the lab partly because I wanted to start experimenting with stockpiling hardware and software as a complementary preservationist strategy to creating emulations such as the one of First Screening that had recently been made available. Without being aware of the very nascent debates in archivist communities that

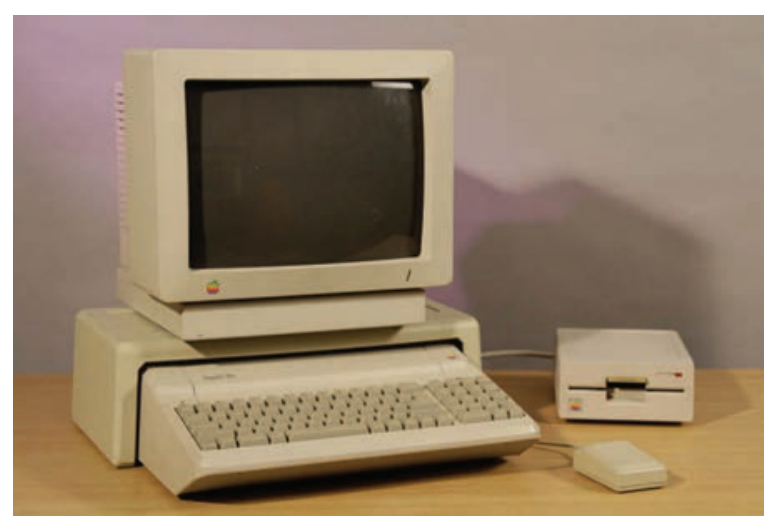

FIGURE 11.1 Apple Platinum IIe computer, from 1987, housed in the Media Archaeology Lab. 


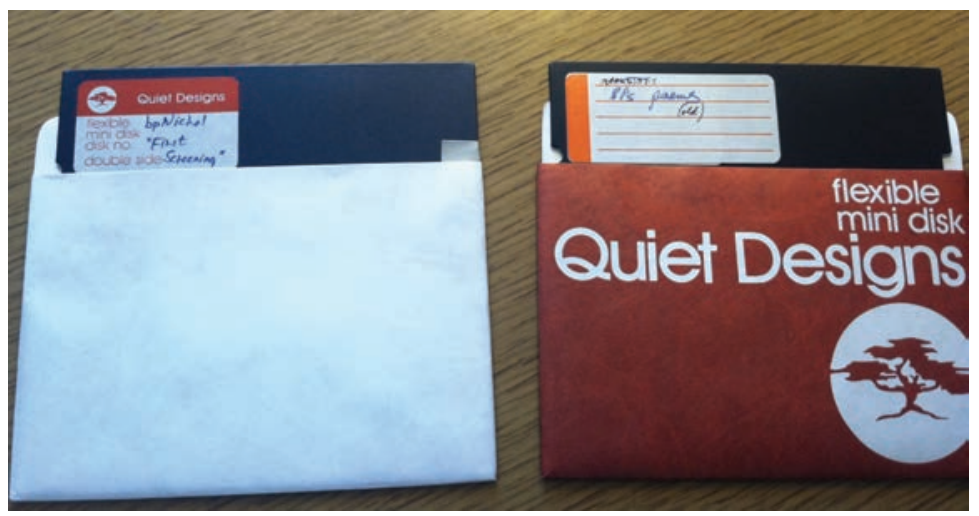

FIGURE 11.2 5.25" floppies of 'manuscript' versions of bpNichol's digital poem "First Screening" from 1982-1983, housed in the Media Archaeology Lab.

were then pitting emulation against original hardware/software, I wanted to augment students' and scholars' access to early works of digital literature and art while also collecting other works and their original platforms in order to eventually make available emulations of these works.

However, I also created the lab because I wanted to bring in small undergraduate and graduate classes to work directly on the machines, with the original work by bpNichol, rather than only study the emulated version. In other words, the lab allowed me to think through with my students the difference the original material, tactile environment makes to our understanding of First Screening. It was a straightforward enough experiment, but even now in 2017, the implications of this kind of literary/historical work are far reaching and unsettling to the discipline. The foregoing first involves turning away from close reading and from studying literary products (as surface effects), to studying instead the literary production process looking at how a literary work was made and how the author pushed up against the limits and possibilities of particular writing media. From there, the ramifications of such an approach start to become more obvious as soon as one realizes that learning and teaching 'the how' of literary production cannot take place without access to the tools themselves in a hands on lab environment. That said, while using hands on work not just as an added feature but as the driving force behind teaching and research is quite new to the humanities, the production-oriented approach to interpreting literature has been around in one form or another since the early twentieth century. As many are fond of pointing out, nearly all foundational media studies scholars (from Walter Benjamin to Marshall McLuhan and Friedrich Kittler) were first literary scholars; moreover, one can read the long history of experimental writers, especially poets, as one that is inherently about experimenting with writing media - whether pens, pencils, paper, or typewriters and personal computers.

Since my academic background is in twentieth-century experimental poetry and poetics, the move to exploring the materiality of early digital poetry was a 
logical next step. Furthermore, once my attention turned to the intertwinement of First Screening with the Apple IIe, it likewise made sense to add to the lab's collection other, comparable personal computers from the early 1980s such as the Commodore 64 - at least partly to get a sense of why bpNichol might have chosen to spend $\$ 1395$ on the IIe rather than $\$ 595$ on the C64. (The answer likely lies in the fact that the IIe was one of the first affordable computers to include uppercase and lowercase along with an 80-column screen, rather than the C64's 40-column display for uppercase letters only.)

In these early years, I tried to sell the lab to the larger public by saying that it was an entity for supporting a locavore approach to sustaining digital literature a pitch I also hoped justified our very modest online presence while also underscoring the necessity of working directly with the machines in the lab rather than accessing, say, an Apple IIe or Commodore 64 emulator online. Thus, from 2009 until 2012, the 'Archaeological Media Lab' maintained its modest collection of early digital literature and hardware/software from the early 1980s and gradually increased its network of supporters - from eBay sellers who had become ardent supporters of the lab, to students and faculty from disciplines ranging from Computer Science, Art, Film Studies, and English literature, to digital archivists. However, 2012 was a turning point for the lab for a number of reasons: first, and most importantly, the lab was given a 1000 square foot space in the basement of an older home on the edge of campus, making it possible for the lab to become the open-ended, experimental space it is today with the largest collections of still-functioning media in North America; second, I renamed the lab the 'Media Archaeology Lab' to better align it with the field of media archaeology I was then immersed in; and third, the MAL became a community enterprise no longer synonymous just with me - now the lab has an international advisory board of scholars, archivists, and entrepreneurs, which I consult every six months, faculty fellows from CU Boulder, a regularly rotating cohort of

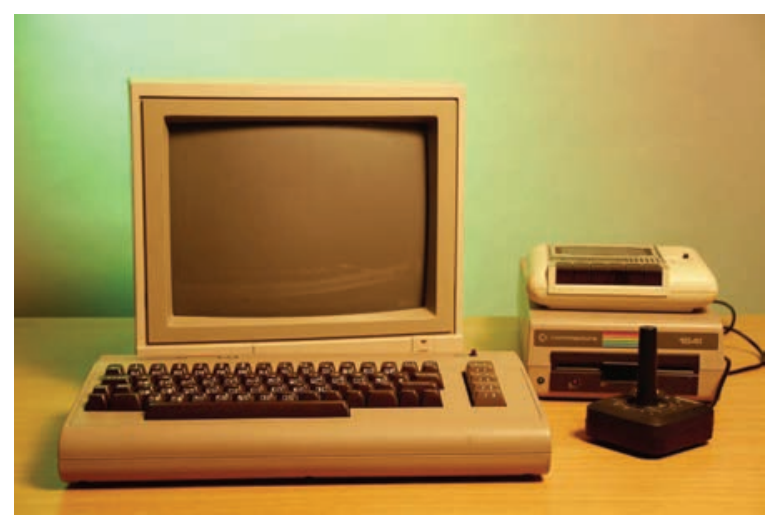

FIGURE 11.3 Commodore 64 computer, from 1982, housed in the Media Archaeology Lab. 
undergraduate interns, graduate research assistants, post-graduate affiliates, and volunteers from the general public.

The lab, called the Media Archaeology Lab since 2012, is also now a kind of anti-museum museum in that all of its hundreds of devices, analogue and digital, are meant to be turned on and actively played with, opened up, tinkered with, experimented with, created with, and moved around and juxtaposed next to any other device. Again, everything that is on display is functional, though we also have a decent stockpile of spare parts and extra devices. The MAL is particularly strong in its collection of personal computers and gaming devices from the 1970s through the 1990s ranging from the Altair $8800 \mathrm{~b}$ (1976), the complete line of Apple desktop computers from an Apple I replica (1976/2012) to models from the early 2000s, desktops from Sweden (1981) and East Germany (1986), a Canon Cat computer (1987 - I discuss this machine in detail in the following section), and game consoles such as Magnavox Odyssey (1972), Video Sports (1977), Intellivision (1979), Atari 2600 (1982), Vectrex (1982), NES (1983) and other Nintendo

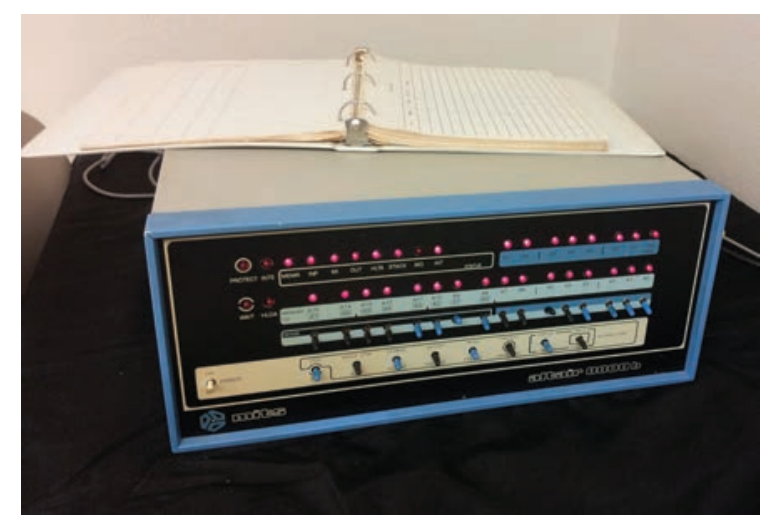

FIGURE 11.4 Altair 8800b computer, from 1976, housed in the Media Archaeology Lab.

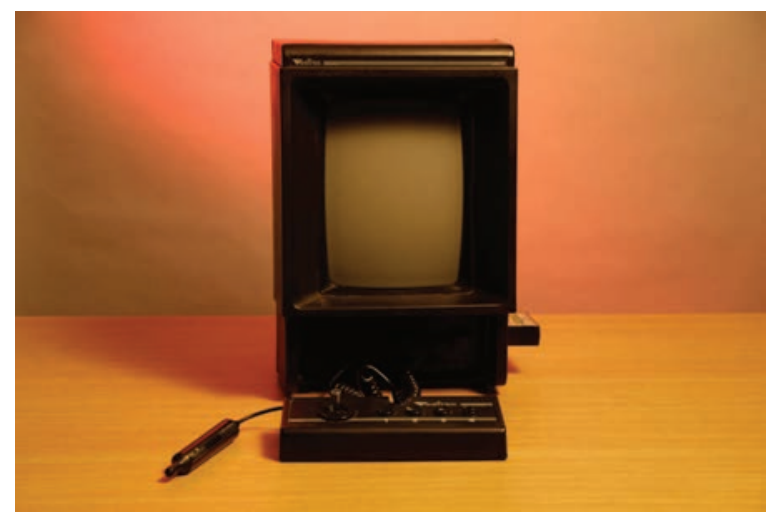

FIGURE 11.5 Vectrex game console, from 1983, housed in the Media Archaeology Lab. 


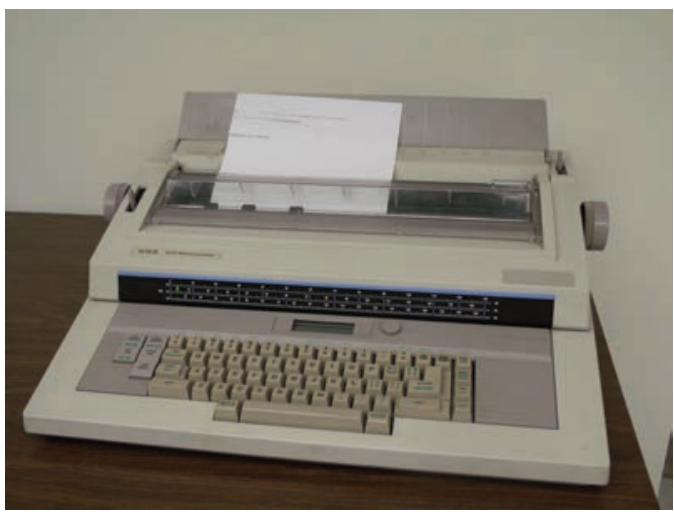

FIGURE 11.6 Xerox typewriter, likely from around 1987, housed in the Media Archaeology Lab.

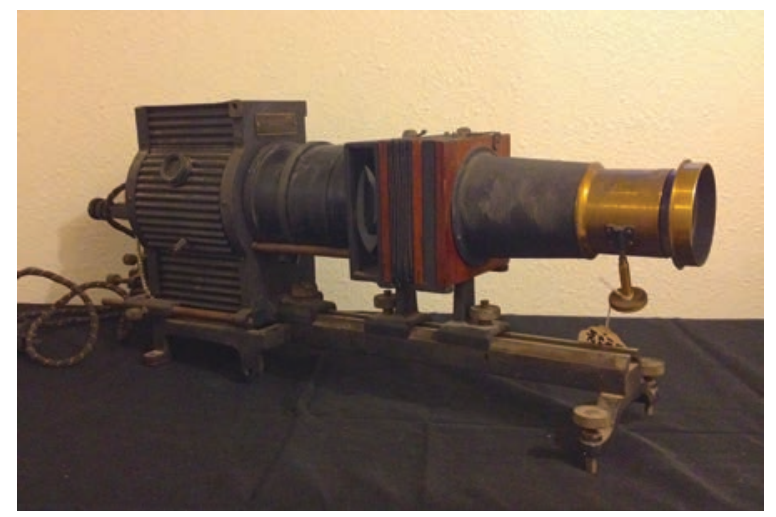

FIGURE 11.7 Magic Lantern, likely from around 1910, housed in the Media Archaeology Lab.

devices. These are just a handful of examples of hundreds of machines in the MAL collection in addition to thousands of pieces of software, magazines, books, and manuals on computing from the 1950s to the present as well as the aforementioned analogue media we house from the nineteenth and twentieth centuries.

\section{A case study in undoing and reimagining computer history: the Canon Cat}

While I am attempting to illustrate the remarkable scope of the MAL's collection, I am also trying to show how anomalies in the collection quietly show how media history, especially the history of computing, is anything but a neat progression of devices simply improving upon and building upon what came before; instead, we can understand the waxing and waning of devices more in terms of a phylogenetic 
tree whereby devices change over time, split into separate branches, hybridize, or are terminated. Importantly, none of these actions (altering, splitting, hybridizing, or terminating) implies a process of technological improvement and thus, rather than stand as a paean to a notion of linear technological history and progress, the MAL acts as a platform for undoing and then reimagining what media history is or could be by way of these anomalies.

The Canon Cat is one of the best examples I've come up with of a machine that disrupts any attempt to narrativize a linear arc of past/present/future that supports notions of progress or even notions of regression. This machine was designed by Jef Raskin after he left Apple in the early 1980s and it was introduced to the public by Canon in 1987 for $\$ 1495$ - roughly $\$ 3316$ in 2017 , the year of this writing. Although the Cat was discontinued after only six months, around 20,000 units were sold during this time. The Canon Cat is a particularly unusual device as it was neither behind the times nor ahead of its time - it was actually very much of its time, albeit a time that does not fit into our usual narrative of the history of personal computing.

First, this machine was marketed as an 'Advanced Work Processor'. Although it looks like a word processor, the Cat was meant to be a step beyond both the IBM Selectric Typewriter and conventional word processors. It came with standard office suite programs, a built-in communications device, a 90,000 word dictionary, and the ability to program in Forth and assembly language. While the Cat was explicitly not a word processor, it was also not supposed to be called a 'personal computer' because its interface was distinctly different from both the commandline interface and the Graphical User Interface (GUI) that, by 1987, had already become inseparable from the idea of a personal computer. Try to imagine a computer that had no concept of files and no concept of menus. Instead, all data was seen as a long 'stream' of text broken into several pages. And so even though the interface was text based (it does not make use of mouse, icons or graphics), its functions were built right into the keyboard. Whereas with a machine that uses a GUI

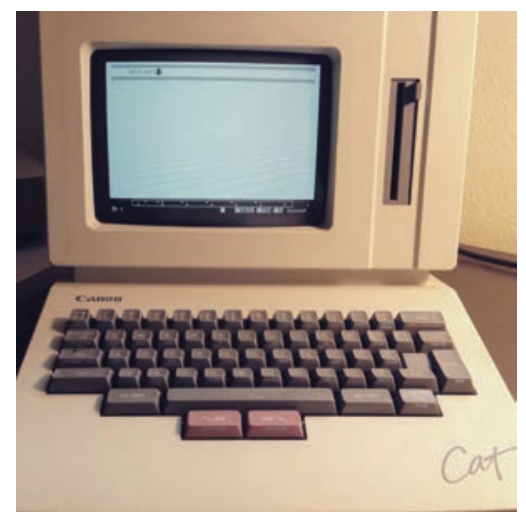

FIGURE 11.8 Canon Cat computer, from 1987, housed in the Media Archaeology Lab. 
you might use the mouse to navigate to a menu and select the command 'FIND', with the Cat you use the 'LEAP' keys.

But before I can explain how LEAP works, I need to explain the remarkable way Raskin designed the cursor, because the cursor is part-and-parcel of the LEAP function. The Cat's cursor has several states: narrow, wide, and extended. In addition to the variable cursor states, the cursor blink rate also indicates the state of the text. The cursor blink rate has two states: clean (whereby the cursor blinks at a rate of roughly $3 \mathrm{~Hz}$ to indicate that all changes to the text have been saved to a disk) and dirty (whereby the cursor blinks at a rate of about $1 \mathrm{~Hz}$ to indicate that changes have been made to the text and they have not been saved to a disk). Leaping, then, is the Cat's method of cursor movement; you can leap forward and backward using the LEAP FORWARD and LEAP BACKWARD keys. While the LEAP FORWARD key is held, a pattern may be typed. While the pattern is being typed, the cursor immediately moves forward and lands on the first character of the first occurrence of the pattern in the text. LEAP BACKWARD behaves the same as LEAP FORWARD except that the cursor moves in the opposite direction through the text. Note that LEAP was, at that time, roughly 50 times faster than the same function on the Apple Macintosh and possibly just as fast as 'FIND' is on our contemporary machines.

I have only discussed two features of the Cat - the cursor functionality and LEAP, both of which make it possible to do many more things than we can do today with FIND or control-F or with our generally single-purpose cursor. My point is that, just on the face of it, the Canon Cat disrupts even the most nuanced genealogical accounts of computers and digital devices. Where does a Work Processor fit in the history of computing - a history that nearly always glides seamlessly from IBM Selectric, to kit computers, mini computers, microcomputers, word processors and personal computers? More, this disruption only becomes evident when you look not at the Cat's outward appearance, its style and design, but at its functionality.

It is also important to note the bundle of contradictions and inaccuracies the Cat's functionality brings to light as they show us the mismatch between what we believe is the history of computing versus the disruptions to this story represented by machines such as the Cat. For example, while, beginning with the Macintosh, Apple may have had an uncanny knack for weaving design into marketing, that certainly wasn't the case across the board. The design and marketing of computers in the 1980s were not necessarily one and the same as Raskin's vision for the machine was consistently contradicted by Canon. For example, Canon sold the Cat as a secretarial workstation and therefore represented it in promotional materials as a closed system. While, in fact, the Cat was designed not only to integrate with third-party software but it also had a connector and software hooks for a pointing device that could be added on later. Moreover, despite Canon's efforts to market the machine as closed, somehow Raskin was able to make sure the Cat came with a repair manual and very detailed schematics for how to dis-assemble and re-assemble every single part of the machine. The Apple Macintosh, by contrast, never came with anything like schematics; in fact, Apple openly discouraged people from 
opening up the Macintosh and repairing it themselves, in the same way that our Apple devices nowadays are similarly hermetically sealed (Emerson 2014). Furthermore, while the Cat was consistently marketed by Canon in terms of its speed and efficiency, reinforcing our belief that these are the two markers of progress when it comes to digital technology, Raskin himself seemed to take pride in making heretical statements about how his designs were based on an "implementation philosophy which demanded generality and human usability over execution speed and efficiency" (quoted in Feinstein 2006). By contrast, every single bit of Canon's promotional material for the Cat - from videos to magazine ads to the manuals themselves - emphasized the machine's incredible speed.

\section{A variantology of hands on practices}

The MAL, then, is essential for exploring the functionality of historically important media objects - functionality that cannot be understood in any depth if one only has access to promotional material or archival documents and that fundamentally shapes one's understanding of the media object's place in the history of technology. Otherwise put, the lab invites one to reread media history in terms of non-linear and non-teleological series of media phenomena - or ruptures - as a way to avoid reinstating a model of media history that tends toward narratives of progress and generally ignores neglected, failed, or dead media.

I have also come to understand the MAL as a sort of 'variantological' space in its own right, a place where, depending on your approach, you will find opportunities for research and teaching in myriad configurations as well as a host of other, less clearly defined activities made possible by a collection of functioning items that are both object and tool. In other words, the lab is both an archive of hardware and software that are themselves objects of research at the same time as the hardware and software generate new research and teaching opportunities.

For example, in terms of the latter, in the last three years the lab's vitality has grown substantially because of the role of three PhD students who are developing their own unique career trajectories in and through the lab. The results have already been extraordinary. One student, who wishes to obtain an academic position after graduation, has created a hands on archive of scanners in conjunction with a dissertation chapter, soon to be published as an article, on the connections between the technical affordances of scanners and online digital archives. Another student, who wishes to obtain a curatorship after graduation, founded an event series called MALfunctions, which pairs nationally and internationally recognized artists with critics on topics related to the MAL collection; this student also arranges residencies at the lab for these visiting artists/critics who, in turn, generate technical reports on their time spent in the MAL; furthermore, as a result of her work with this event series, this student has been invited to be a curator for annual media arts festivals and local museums and galleries. Yet another student, who wishes to pursue a career in alternative modes of teaching and learning, has started a monthly retro games night targeted specifically for members of the LGBTQ community 
at $\mathrm{CU}$; she also is running monthly workshops teaching students and members of the public how to fix vintage computers and game consoles as well as the basics of surveillance and privacy; as a result of her work, this student was invited to run a workshop at the Red Hat Summit in Boston, MA in Spring 2017.

In sum, the MAL is unique for a number of reasons. Rather than being hierarchical and classificatory both in its display of objects as well as its administrative organization of people, the MAL is porous, flat, and branching; objects are organized in any way participants want; everything is functional and made to be turned on. Rather than setting out to adhere to specific outcomes and five year plans, we change from semester to semester and year to year depending on who's spending time in the lab. Rather than being an entity you need to apply to be a part of or something you can only participate in as a researcher, librarian, PhD student, anyone may participate in the lab and have a say about what projects we take on, what kinds of work we do. Rather than being about the display of precious objects whereby you only ever get a sense of the external appearance or even external functionality of the objects, we encourage people to tinker, play, open things up, disassemble. Rather than the perpetuation of neat, historical narratives about how things came to be, we encourage an experimental approach to time - put Edison disks beside contemporary proprietary software or put the Vectrex and its lightpen up next to a contemporary tablet and stylus to see what we can learn through the juxtapositions. And finally, rather than participating in the process of erasing the knowledge production process or perpetuating the illusion of a separation between those who work in the lab and the machines they work on and hiding the agency of the machines themselves as well as the agency of the larger infrastructure of the lab, we are interested in constantly situating anything and everything we do in the lab and being self-conscious, descriptive about the minute particularities of the production process for any projects we undertake.

In short, it's my hope that the MAL can be a tool for moving away from humanism and traditional humanities work and instead tentatively, provisionally model what posthumanities work might look like.

\section{Bibliography}

Braidotti, Rosi. (2013) The Posthuman. Oxford, UK: Polity, 143.

Emerson, Lori. (2014) Reading Writing Interfaces: From the Digital to the Bookbound. Minneapolis, MN: University of Minnesota Press, 47-85.

Feinstein, Jonathan S. (2006) The Nature of Creative Development. Stanford, CA: Stanford University Press, 148.

Haraway, Donna. (1988) Situated Knowledges: The Science Question in Feminism and the Privilege of Partial Perspective. Feminist Studies, 14(3) (Autumn): 575-599.

Latour, Bruno and Steve Woolgar. (1986) Laboratory Life: The Construction of Scientific Facts. 2nd edition. Princeton, NJ: Princeton University Press, 240.

Moretti, Franco. (2003) Graphs, Maps, and Trees: Abstract Models for Literary History. New Left Review 24 (November-December): 67-93. 